\title{
Bullying in the Countryside: Prevalence, Factors and Coping Mechanism
}

\author{
Jonathan P. Wong \\ Associate Professor \\ Romblon State University - Romblon Campus \\ Amaranth M. Wong \\ Master Teacher II \\ San Jose Elementary School - Romblon, Romblon
}

\begin{abstract}
Bullying though old is now becoming widespread and a worldwide problem especially among schools. Incidence of bullying even in the countryside are becoming observable. The prevalence of bullying needs special attention as current literature confirm its adverse effect to both the bully and the bullied. This study was initiated primarily to determine the common bullying experiences of pupils in two central schools in the province of Romblon, Philippines that may serve as basis for an effective guidance and counseling program for bullying problems. The study is descriptive in nature employing a combination of quantitative and qualitative method using questionnaire and interview as techniques in gathering the data. A total of $\mathbf{1 8 7}$ grade VI pupils, two school heads from two central schools in the District of Romblon, Division of Romblon participated in the study. Findings revealed that the most prevalent physical bullying experienced by the respondents are: being pushed, punched and kicked. These happens more than once to 7 out of 10 pupils. The most common verbal bullying experienced by the respondents are: being insulted, spoken with bad words and being teased. These happens more than once to 6 to 8 pupils out of 10. The usual coping mechanism done by the respondents when bullied includes: telling their parents, teachers and friends. The factors associated with bullying behavior are: a)in terms of family, harsh discipline from parents; b)in terms of peer, influenced by friends; c)in terms of school, lack of policy against bullying; and d)in terms of environment, exposure to violent films and.
\end{abstract}

Key words: Bullying, Physical bullying, Verbal bullying

\section{INTRODUCTION}

Bullying among children is quite common and is not a new phenomenon. Most adults may have experienced being bullied or the other way around. However there seems to be a difference in the way bullying today is exhibited compared before. The prevalence of bullying and its adverse effects are also to be considered in distinguishing bullying before and bullying today. News of students committing suicide because of being bullied in social media is becoming frequent. Such incidence may have been uncommon before. Bullying usually affects both the victim and the bully both physically and psychologically. The British Medical Journal published a report that among the health problems encountered by those who are bullied includes eating and sleep disorders, headaches and stomach aches (William et al., 1996). Other studies also acknowledged bullying behavior in elementary school as precursor of violent behavior and show significant link between this behavior and criminal activity in adult life. Anxiety, low selfesteem, and depression problems are also attributed to bullying experienced repeatedly by 
children. Bullying comes in many forms and sizes either physical, verbal or the more popular one commonly called cyber bullying.

The school is among those places where bullying is reported to have shown high percentage of bullying incidence. This is because children with diverse culture, background, personality and status meet there. Schools having a bigger number of student population may show greater risk of bullying incidence and requires a sound guidance program starting from prevention and cure. All types of schools be it private and public, city or in countryside are vulnerable to bullying incidence. As the bullying phenomenon is becoming widespread, schools are encouraged to really make the necessary program that may prevent to some degree the occurrence of such problem and thus lessen its traumatic effect to the students. Such program should be based on empirical study conducted by school authorities. With bullying incidence becoming far-reaching, numerous studies about bullying had also been done. However, there appears limited studies about bullying in the countryside similar to the present investigation.

\section{RESEARCH OBJECTIVES}

This study aims to determine the common bullying experiences encountered by public elementary school pupils as well as the factors associated with the bullying behavior in selected public central schools within the district of Romblon.

Specifically, it sought answers to the following questions:

1. What are the common bullying experiences encountered by the pupils either verbal or physical?

2. What are the factors associated with the bullying behavior as perceived by the pupils?

3. What are the coping mechanism of pupils who have been bullied?

4. What are the programs done by schools to address the bullying problem?

\section{METHODOLOGY}

Since this study is descriptive in nature, the survey method was used. Through the survey with the use of questionnaire and interview techniques, the common bullying experiences encountered by the pupils either verbal or physical along with the factors associated with it, and their coping mechanism were clearly described.

\section{Respondents of the Study}

The study included a total of 187 grade six pupils from the two (2) central schools in the District of Romblon. Complete enumeration was used in the study considering that almost the entire population of grade six pupils in the said schools were involved. These schools were selected purposively due to its big population.

\section{Research Instrument}

The main instrument used in gathering data was the questionnaire and structured interview which was constructed based on the statement of the problem and related studies. Part one of the questionnaire deals with the bullying experiences encountered by the pupils either verbal or physical Part two deals with the factors associated with the bullying behavior as perceived by the pupils. Part three is about the coping mechanism of pupils who have been bullied. Part four deals with the programs done by schools to address the bullying problem. The content validation of instrument was done by three experts and was found to be relevant. 


\section{Data Processing and Analysis}

The data gathered in this study were tallied and tabulated for statistical analysis. The descriptive statistical tools used for the analysis of data includes frequency count and percentage. This study made use of both quantitative and qualitative method of data analysis.

\section{RESULTS}

\section{Physical bullying experiences encountered by the respondents}

Shown in table 1 is the frequency of bullying behavior encountered by the respondents in terms of physical in the two central elementary schools in the District of Romblon. Based from the table, out of 187 respondents, 59 or $31.55 \%$ of them have been punched or hit by their schoolmate at least once and 64 or $34.22 \%$ of them experienced the same kind of physical bullying more than once. It appears that a total of 123 or $65.78 \%$ of the pupils experienced punching or hitting as a form of physical bullying. This suggest that in every 10 pupils, 7 of them may possibly be bullied physically through punching or hitting.

Pushing as a form of physical bullying was experienced at least once by 64 or $34.22 \%$ of the respondents and more than once by 70 or $37.43 \%$. It can be deduced that a total of 134 out of 187 with a ratio of 7 out of 10 experienced pushing as a form of physical bullying.

Kicking as a form of physical bullying was experienced at least once by 41 or $21.93 \%$ of the respondents and more than once by 47 or $25.13 \%$. A total of 88 out of 187 with a ratio of 5 out of 10 experienced kicking as a form of physical bullying.

When it comes to money or food being stolen, 9 or $4.81 \%$ of them said that it happened to them once while 11 or $5.88 \%$ of them said that it occurred more than once. The data indicates that out of 187,20 or $10.70 \%$ of the respondents have experienced to be stolen with money or food suggesting a 1 is to 10 ratio.

Damaging belongings accumulated a total of 74 or $39.57 \%$ and out of this number 34 or $18.18 \%$ of them experienced it more than once while 40 or $21.39 \%$ of them experienced it only once.

Table 1. Physical bullying experiences encountered by the respondents

\begin{tabular}{|c|c|c|c|c|c|c|}
\hline \multirow[t]{2}{*}{ Bullying experiences } & \multicolumn{2}{|c|}{ Once } & \multicolumn{2}{|c|}{$\begin{array}{c}\text { More than } \\
\text { once }\end{array}$} & \multicolumn{2}{|c|}{ Never } \\
\hline & $\mathrm{f}$ & $\%$ & $\mathrm{f}$ & $\%$ & $\mathrm{f}$ & $\%$ \\
\hline 1. My schoolmate punched/hit me & 59 & 31.55 & 64 & 34.22 & 64 & 34.22 \\
\hline 2. My schoolmate pushed me & 64 & 34.22 & 70 & 37.43 & 53 & 28.34 \\
\hline 3. My schoolmate kicked me & 41 & 21.93 & 47 & 25.13 & 99 & 52.94 \\
\hline 4. My schoolmate stole my money/food & 9 & 4.81 & 11 & 5.88 & 167 & 89.30 \\
\hline 5. My schoolmate damaged my belongings & 40 & 21.39 & 34 & 18.18 & 113 & 60.43 \\
\hline
\end{tabular}

\section{Verbal bullying experiences encountered by the respondents}

Table 2 shows the frequency of bullying behavior in terms of verbal. 68 or $36.36 \%$ experienced to be insulted by a schoolmate once while 90 or $47.06 \%$ experienced the same kind of verbal bullying more than once. A total of 158 out of 187 experienced insult as a form of verbal bullying. This suggest that 8 out of 10 pupils may possibly be bullied verbally through insult. 
33 or $17.65 \%$ of the respondents said that their schoolmate made fun of them through name calling only once while 80 or $42.78 \%$ said that they experienced the same more than once. A total of 113 out of 187 suggest a 6 out of 10 ratio.

Teasing as a form of verbal bullying was experienced by $62.57 \%$ or 117 respondents. 32 or 17.11 of them experienced it once while 85 or $45.45 \%$ experienced the same more than once. This suggest that 6 out of 10 pupils may possibly be bullied verbally through teasing.

A total of $73.80 \%$ or 138 respondents admitted that their schoolmate said bad words to them. 51 or $27.27 \%$ among them experienced it once while 87 or $46.52 \%$ experienced the same more than once. This means that 7 out of 10 pupils experienced this form of verbal bullying.

Criticism as a form of verbal bullying garnered 53 or $28.34 \%$. Out of this number, 24 or $12.83 \%$ experienced it once while 29 or $15.15 \%$ experienced it more than once. This suggest that 3 out of 10 may possibly be bullied verbally through criticism.

Table 2. Verbal bullying experiences encountered by the respondents

\begin{tabular}{|c|c|c|c|c|c|c|}
\hline \multirow[t]{2}{*}{ Bullying experiences } & \multicolumn{2}{|c|}{ Once } & \multicolumn{2}{|c|}{$\begin{array}{l}\text { More than } \\
\text { once }\end{array}$} & \multicolumn{2}{|c|}{ Never } \\
\hline & $f$ & $\%$ & $f$ & $\%$ & $f$ & $\%$ \\
\hline 1. My schoolmate insulted me & 68 & 36.36 & 90 & 47.06 & 31 & 16.58 \\
\hline 2. My schoolmate made fun of me through name calling & 33 & 17.65 & 80 & 42.78 & 74 & 39.57 \\
\hline 3. My schoolmate teased me & 32 & 17.11 & 85 & 45.45 & 70 & 37.43 \\
\hline 4. My schoolmate said bad words to me & 51 & 27.27 & 87 & 46.52 & 49 & 26.20 \\
\hline 5. My schoolmate criticized me/my family & 24 & 12.83 & 29 & 15.51 & 135 & 71.66 \\
\hline
\end{tabular}

\section{Coping mechanism of respondents who experienced bullying}

Table 3 indicates the coping mechanism of the respondents who experienced bullying. Among the mechanisms, telling their teacher obtained the highest frequency distribution of 103 or $55.08 \%$ followed by telling their parents and their friends with the same frequency distribution of 96 or $51.34 \%$. Next is they ignore it with frequency distribution of 88 or $47.06 \%$. Staying away from school received the lowest frequency distribution of 20 or $10.70 \%$.

The data reveal that the most common coping mechanism done by the victims of bullying behavior is telling their teacher which is ranked first. Others coped up by telling their parents and friends occupying the same rank. Staying away from school is the least coping mechanism done by the respondents. These coping mechanisms are still considered to be positive in reference to Cary Sweatrer (2003), findings that many times victims will commonly respond to bullying through escape and avoidance behaviors, such as not attending school, refusal to go to certain locations, running away from home, and in some extreme cases, attempting suicide. The coping mechanisms of the respondents in this study may be due to the reason that they have close connection to their parents of which they resort to telling them about the incident rather than staying away from school.

The study however did not look on whether or not these coping mechanism are effective. Parents and teachers of the respondents were also not asked as to the number of times their kids or pupils reported being bullied or what common bullying behavior are usually done to them. 
Mechanism

Table 3. Coping mechanism of respondents who experienced bullying

1. I retaliate

2. I ignore it

3. I run away

4. I tell my teacher

5. I tell my parents

6. I tell my friends

7. I stayed away from school

8. I plan revenge

\section{$\mathrm{f}$}

50

$88 \quad 47.06$

$54 \quad 28.28$

$103 \quad 55.08$

$96 \quad 51.34$

$96 \quad 51.34$

$20 \quad 10.70$

$35 \quad 18.72$
Rank

5

2

4

1

2

2

7

6

\section{Factors associated with bullying behavior}

Shown in table 4 are the factors associated with bullying behavior as perceived by respondents. When asked as to why their schoolmates are involved in bullying activity, most of them believed that in terms of family, harsh discipline from parents is the main reason obtaining the highest frequency of 49 or $26.20 \%$, followed by lack of supervision by parents having a frequency distribution of 37 or $19.79 \%$. Broken family garnered a frequency of 36 or $19.25 \%$ and lastly is the permissive parents which got the lowest frequency of 34 or $18.18 \%$.

In terms of peer, influenced by friends got the highest frequency of 90 or $48.13 \%$ while being forced by peers got the lowest frequency of 40 or $21.39 \%$.

In the terms of school, lack of policy against bullying obtained the highest frequency of 48 or $25.67 \%$ followed by the lack of supervision during recess/ lunch break which has a frequency of 45 or $24.06 \%$. Last is the lack of school discipline which obtained the frequency of 33 or $17.65 \%$.

In terms of environment, most of the respondents said that, exposure to violent films may have been a factor with a frequency of 58 or $31.02 \%$.

It appears that based from the result, harsh discipline from parents, friends' influence, lack of policy against bullying and exposure to violent films are believed to be among those common factors associated with bullying behavior. The findings however is limited only to the general perception of the respondents whom may not have been involved in bullying behavior against their schoolmates.

The result somehow agrees to Bank (2000), who observed that some children are at more risk of becoming bullies and victims than others, although this is in no way predetermined. It depends on a combination of individual, family, peer, and school experiences. 


\begin{tabular}{|c|c|c|c|}
\hline A. Family & $\mathrm{f}$ & $\%$ & Rank \\
\hline 1. Permissive parents & 34 & 18.18 & 4 \\
\hline 2. Broken family & 36 & 19.25 & 3 \\
\hline 3. Harsh discipline from parents & 49 & 26.20 & 1 \\
\hline 4. Lack supervision by parents & 37 & 19.79 & 2 \\
\hline \multicolumn{4}{|l|}{ B. Peer } \\
\hline 1.influenced by friends & 90 & 48.13 & 1 \\
\hline 2. Forced by peers & 40 & 21.39 & 2 \\
\hline
\end{tabular}

\section{School}

1. Lack of school discipline

$33 \quad 17.65 \quad 3$

2. Lack of policy against bullying

$\begin{array}{lll}48 & 25.67 \quad 1\end{array}$

3. Lack of supervision during recess/lunch break

$45 \quad 24.06 \quad 2$

\section{Environment}

1. Exposure to violent films

$\begin{array}{lll}58 & 31.02 & 1\end{array}$

\section{Programs done by the schools to address the bullying problem}

Based on the interview conducted to the school heads of the two central schools covered in this study, the following are the programs done to address the bullying problem namely: counseling both to the bully and the bullied pupils and seminar on children's right. Although these programs are appropriate, they are still inadequate as the problem of bullying is becoming rampant.

\section{DISCUSSION}

It can be gleaned from this result that among the physical bullying experienced by pupils, being pushed is the most common which account to $71.65 \%$. This is followed by being punched, kicked, their belongings being damaged and food or money being stolen as the least. In addition, most of these physical bullying behavior occurred to the respondents more than once. These bullying experiences are in the form of physical that involves behavior such as the perpetrator might punch, hit and \or steal money from victims (Crick, Nelson, Morale, Cullerton-Sen, Casa and Hickman, 2001). Rigby (2001), on her findings on bullying indicated that bullying is a physically harmful, psychologically damaging and socially isolating aspect of a large number of children's school experience. Studies had also highlighted that children who are bullied have a higher level of stress, anxiety, depression and illness, and an increased tendency to suicide. It is however not the scope of the present study to investigate the effects of such physical bullying encountered by the respondents.

The result likewise indicates the prevalence of verbal bullying behavior among the two (2) schools. Among these verbal behaviors, the most common are being insulted, being spoken with bad words and being teased. Moreover, these verbal bullying occurred to them more than once. These findings indicates the existence of various forms of bullying as emphasized by Crick, Nelson, Morale, Cullerton-Sen, Casa and Hickman (2001), that there exist three forms of bullying: physical, verbal and relational. Verbal bullying includes behavior such as the perpetrator making rude remarks and $\backslash$ or name calling toward a victims. Rational bullying also known as indirect bullying. Also, Olsen (2006), explained that bullying consist of both indirect 
and direct behavior. Direct behaviors, which are more commonly seen in boys, consist of calling names, teasing, taunting, threatening, hitting, using a weapon, and stealing by one or more individuals against a victim. While bullying behavior of boys is usually more direct in nature, girls tend to use more subtle tactics, which can be more indirect in nature. In-direct behaviors includes spreading rumors, exclusion or isolation from peers, and or manipulating relationships and or friendships. In fact bullying victims are also isolated by other non-bullying peers, because these peers do not want to be associated with a victim of bullying due to the threat of becoming a victim themselves.

Although it was stressed earlier that children who are bullied have a higher level of stress, anxiety, depression and illness, and an increased tendency to suicide, this study was limited as to whether or not these effects were manifested by the respondents. In addition, literature also vary as to which type of bullying verbal or physical has more adverse effect to the bullied.

The survey result further indicates that harsh discipline from parents, friends' influence, lack of policy against bullying and exposure to violent films are believed to be among those common factors associated with bullying behavior. The findings however is limited only to the general perception of the respondents whom may not have been involved in bullying behavior against their schoolmates. The result somehow agrees to Bank (2000), who observed that some children are at more risk of becoming bullies and victims than others, although this is in no way predetermined. It depends on a combination of individual, family, peer, and school experiences.

\section{Implication to guidance and counselling program}

The study revealed that respondents from the two central schools have experienced various types of bullying behavior from their schoolmates. They encountered such bullying behavior more than once and the possibility of repeating such behavior is high if schools will not integrate into their guidance and counselling program a comprehensive framework that may lessen if not prevent the occurrence of such bullying problem. The framework may include the involvement of various stakeholders so as to make the school a safe environment. The effects of bullying are far-reaching, and should not be taken lightly by school authorities which includes lower attendance and student achievement to increased violence and juvenile crime, and not only does it harm victims and perpetrators, it affects the school environment, teachers disposition, and indirectly students' academic performance and their ability to learn. As the problem of bullying becomes apparent, widespread and rampant, schools in the countryside should not be complacent as they are also becoming vulnerable due to the increasing number of student population and the availability of social media. School authorities from the countryside may now set aside the idea that bullying incidents are common only to city schools and that students from the provinces are far more disciplined and behaved. Reports of bullying incidents from the countryside are now becoming evident thus requiring a comprehensive framework into their guidance and counselling program to prevent or reduce bullying problems to its barest minimum level. As one of the most persistent and destructive forms of violence, bullying deserves the attention of everyone especially the guidance personnel.

\section{CONCLUSIONS}

Based on the findings derived from the study, the following conclusions are drawn:

1. The most common physical bullying experienced by the respondents are: being pushed, punched and kicked. These happens more than once to 7 out of 10 pupils. 
2. The most common verbal bullying experienced by the respondents are: being insulted, spoken with bad words and being teased. These happens more than once to 6 to 8 pupils out of 10 .

3. The most common coping mechanism done by the respondents when bullied are: telling their parents, teachers and friends.

4. The most common factors associated with bullying behavior are:

a) In terms of family, harsh discipline from parents

b) In terms of peer, influenced by friends

c) In terms of school, lack of policy against bullying

d) In terms of environment, exposure to violent films.

5. Programs done by the schools to address the bullying problems are still limited.

\section{RECOMMENDATIONS}

In the light of the findings and conclusions of the present investigation, the following recommendations are hereby offered:

1. The school may create policy against bullying.

2. The school may provide counseling and support for student at risk of being involved in bullying.

3. The parents and teachers must recognize the danger of violent films and discourage their children or pupils from watching them.

4. The school should have supervision to their pupils during break time or recess time.

5. The school may provide a school-wide education, training and bullying prevention programs.

\section{References}

Asamu, F. F. (2006). Correlates of bullying among secondary student in Ibadan, North East Local Government Area of Oyo State. A published M. Ed Thesis of Obafemi Awoloao University, Ile-Ile, Nigereria. Retrieved from http://www.Cor/bul/02_OAU

Bank, R. (2000). Bullying and Victimization. Clearing House On Elementary Childhood Education. National Crime Centre of Canada. Retrieved from http://www.eric database

Burger (2005). Short Term of Bullying, Child Development 74(1), 205-220. Retrieved From

http://www.bing.com/search?FORM=UP22DF\&PC=UP22\&dt=040213

\&q=burger+2005+about+short+term+effects

Carvalho Filho. (2004). Relational aggression, Bullying in the Philippine Setting. Retrieved from http://safeschoolenvironment.blogspot.com/2007/06/bullying- in-philippine-setting.html

Cary Sweatrer (2003). The effects of bullying, Social Development. Retrieved from http://tweenparenting.about.com/od/socialdevelopment/a/Effects-of-Bullying.htm

Crick, N. R., Nelson, D. A., Morales, J. R., Cullerton-Sen, C., Casas, J. F., \& Hickman, S. E. (2001). Relational victimization in childhood and adolescence. Retrieved from http://www.rel_vic_childhoodadolescence/01(2356)

Duba. (1985). Guidance in Philippine Setting. Retrieved from http://safeschool environment.blogspot.com/

Danlheimer. (2004). Bullying-Tremendous Problem. Retrieved from www.clcrc.org/Inside\%20Carter\%20Lake/ICL-pdf

Hoover, J. (2000). Correlates of bullying and victimization among intermediate students in the Midwestern USA. School Psychology International, 21(1) 65. Retrieved from Correlates_bullying\&victimization.blogspot.com/

Hawker, D. S. J. \& Boulton, M.J. (2000). Twenty years of research on peer victimization and psychological maladjustment: A Meta analytic review of cross-section studies. Journal of Child Psychological and Psychiatry, 41, pp. 441-445. Retrieved from http:/www.metaanalyticreview. blogspot.com/

McIntyre, (2003). Dealing bullying: Behavior Advisory. Retrieved from http://max weber, hunter, cury edu/pub/eres/ EDSPC715. MCINTRYRE/ Bullying.hl 
Miriam Defensor Santiago. (2011). Senate Bill No. 2677. ANTI-BULLYING SCHOOL POLICY ACT. Retrieved from http://www.senate.gov.ph/lis/bill_res.aspx? congress=15\&q=SBN-2677

Miguel-Baquilod. (2004). Department of Health Manila. Bullying. Retrieved from http://safeschoolenvironment.blogspot.com/

Nansel, T. R. Overpeck, M., Pilla, R. S., Ruan, W. J., Simons-Morton, B., \& Schdild, P. (2001). Bullying Behavior among U.S youth: Prevalence and association with psychosocial adjustment. Journal of America Medical Association. 285, 16, pp. 2094-2100. Retrieved from http:/www.eric

Nikel et al. (2005). Bullying as Intentional. Retrieved from http://www2.Lurriechild. org/ce/online/article.aspx?articleID=151.

Olweus, D. (1993). Bullying victims problems among school children: Long-term consequences and an effective intervention program. Mental Disorder and Crime. Newbury Park, CA: Sage, pp. 3317-349. Retrieved from http://www.victims_bullyingproblemNewbury01(2)

Olsen, G. (2006). Teasing and bullying in preschool and primary grades: what to do? Early Childhood Education Conference. Retrieved from http://www.UW_stout

Rigby, K. (2001). Stop the bullying: a hand book for Schools. Retrieved from http://www.

Bullying_handbook.blogspot.com/

U.S Department of Health and Human Services. (2001). Youth violence: A report of the surgeon general. Center for the study of prevention of violence. Retrieved from http://www.UShealth/humanservices. blogspot.com/

Ziemen, K. (2006). My Journey: growing up a bully victims. Early childhood Conference. Retrieved from http://www.UW_stout 